\title{
New fissure-attached nodules in lung cancer screening: more practical implications from the NELSON study?
}

\author{
Helen Morgan ${ }^{1}$, Emma L. O’Dowd ${ }^{1}$, Arjun Nair ${ }^{2}$, David R. Baldwin ${ }^{1 \wedge}$ \\ ${ }^{1}$ Respiratory Medicine Unit, David Evans Research Centre, Nottingham University Hospitals, City Campus, UK; ${ }^{2}$ Department of Radiology, \\ University College Hospital, London, UK \\ Correspondence to: David R. Baldwin, MD, FRCP. Respiratory Medicine Unit, David Evans Research Centre, Nottingham University Hospitals, City \\ Campus, Hucknall Road, Nottingham NG5 1PB, UK. Email: david.baldwin@nuh.nhs.uk.
}

Submitted Apr 22, 2020. Accepted for publication Jun 09, 2020.

doi: $10.21037 /$ tlcr-20-586

View this article at: http://dx.doi.org/10.21037/tlcr-20-586

The Dutch-Belgian NELSON trial recently confirmed that screening for lung cancer with low radiation dose computed tomography (LDCT) reduces lung cancer mortality (1). This is a major contribution and has been long-awaited by some countries to support calls for implementation of screening programmes. NELSON has also provided invaluable information about pulmonary nodules and how they should be managed—applied by guideline development committees both in the context of screening and when they are detected incidentally. The volume-based evaluation of nodules allows relatively accurate determination of the baseline risk of malignancy and more accurate assessment of growth (2). The findings have influenced the recommendations in 2 key guidelines $(3,4)$.

Perifissural nodules (PFNs) are widely considered benign findings, usually corresponding pathologically to benign intrapulmonary lymph nodes (5). Guidelines recommend that these nodules are not followed unless there are atypical features or when they are not true PFNs $(3,4)$. Typical PFNs are located within $1 \mathrm{~cm}$ of a fissure or pleural surface, and are small, solid in appearance with a smooth margin and a triangular or lentiform shape (Figure 1) (5). Atypical PFNs either have typical appearances but are not associated with a visible fissure, or have one convex side, and another rounded. Non-PFNs include nodules with other appearances, such as a spherical appearance, or spiculation.
Non-PFNs should be treated in line with guidance for other pulmonary nodules.

In a new paper by Han et al., the subject of new (incident) fissure-attached nodules is addressed (6). The nodules were detected in any one of 3 incident screening rounds. A total of 1,484 new solid nodules were found, of which 107 were fissure-attached and 97 were evaluated in the final results (in 95 participants) (6). These were assessed by two independent NELSON radiologists for features of 'typical PFN', 'atypical PFN' or 'non-PFN'. Where there was discordance in the opinion a third NELSON radiologist arbitrated. Fifty-eight (60\%) of all fissure attached nodules were PFNs, with 42 (43\%) typical, 16 (17\%) atypical, and 39 (40\%) non-PFNs. Only $4 \%$ of new nodules were typical or atypical PFNs, substantially fewer than at baseline (23\%) (5). Overall, in NELSON, of the 7,557 participants, $50.5 \%$ had a total of 8,623 non-calcified pulmonary nodules, of which 98.0\% were solid at the baseline scan, so overall, new PFNs comprised only $0.6 \%$ of all nodules detected in the trial over 5.5 years (7). No typical or atypical PFNs were malignant but $25 \%$ of the non-PFNs were malignant (compared to only $2 \%$ at baseline). Non-PFNs were significantly larger than both the PFNs and benign non-PFNs: malignant nonPFNs had a median volume of $108 \mathrm{~mm}^{3}$ (equivalent and mean diameter of $6 \mathrm{~mm}$ ) compared to $51 \mathrm{~mm}^{3}$ (equivalent and mean diameter of $5 \mathrm{~mm}$ ) for benign non-PFNs.

^ ORCID: 0000-0001-8410-7160 


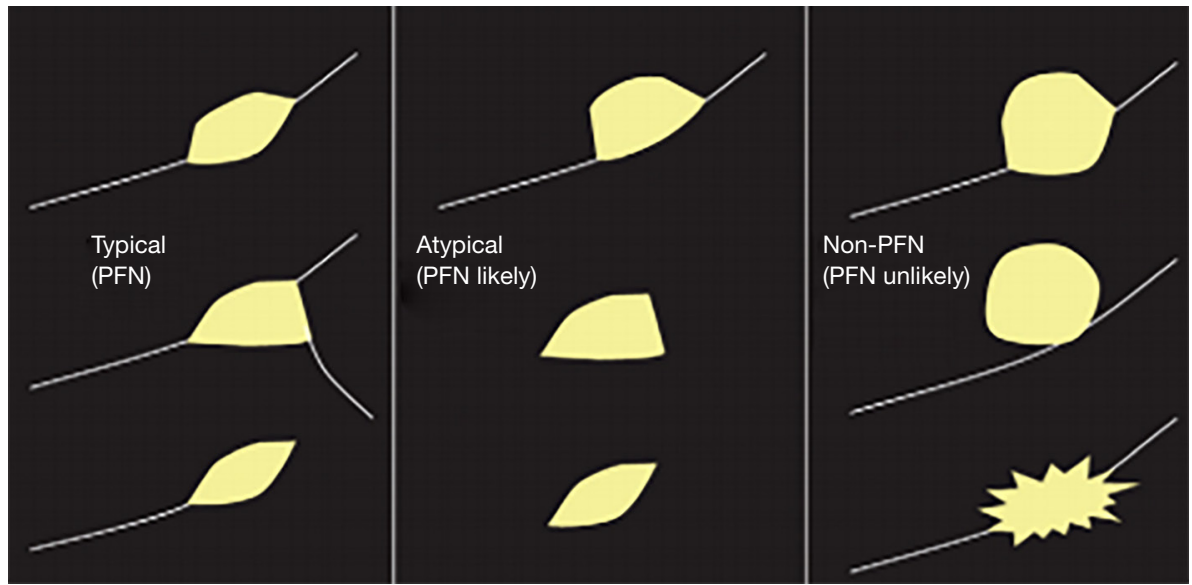

Figure 1 Radiological features of PFNs (de Hoop et al., with permission). PFNs, perifissural nodules.

The investigators acknowledge that the findings are limited by the relatively small numbers of PFNs. They note that several other studies have reported that all PFNs are benign. However, they cite one much larger study using National Lung Cancer Screening Trial (NLST) data enriched with malignant nodules (8). This study included 316 potential PFNs of which 70 were malignant (a much higher rate than in clinical practice, even for solid noncalcified nodules). Although malignant nodules were "misclassified" as PFNs and atypical PFNs, the main findings were that the 6 expert radiologists who evaluated the nodules were unable to agree. Agreement by 2 or more radiologists was only reached for $42 \%$ of PFNs and $32 \%$ of atypical PFNs. Agreement by all 6 radiologists was found in $2 \%$ and $0 \%$ respectively. This is despite including only those studies with $\leq 2 \mathrm{~mm}$ slice thickness. It is likely, therefore, that the accuracy of the assessment of nodules is of paramount importance.

So how may the findings from the NELSON trial once again influence practice and what further work needs to be done? Firstly, it is likely that typical PFNs found on incident imaging are similar to those found at baseline in terms of the rate of malignancy, provided that they are correctly classified. The number of atypical PFNs (16 nodules) was probably too small to make a similar conclusion so, followup of these nodules, either as part of ongoing screening, or by interval scanning should continue as currently recommended.

Secondly, the study shows the benefit of accurate classification achieved by a combination of expertise, consensus and high-quality imaging. In the NELSON trial high quality images were double-reported, with arbitration by a third radiologist. Furthermore, the image reconstruction was more favourable than that in the NLST and the use of semi-automated volumetry was routine. The importance of this volumetric segmentation is reinforced yet again in this study by the fact that malignant non-PFNs had a median volume of more than double that of benign non-PFNs, while the diameter differences were within the limits of interobserver variation and indeed, would not have qualified as unequivocal growth under existing diameterbased screening guidance (9). It is therefore essential in clinical practice to ensure image quality is good, latest reconstruction techniques are used, and volumetry is employed where possible $(3,4,10)$. Despite this, there are only two major guidelines that mandate volumetry as the preferred method to assess nodules $(3,10)$. Whilst this is principally to assess risk of malignancy and growth rate, the images provided by the software may help radiologists to classify fissure-associated nodules. In practice, it is unlikely that many healthcare systems will have sufficient radiology resource to double report each CT, either in the screening setting, or when nodules are detected incidentally. The use of radiographers as second readers has been suggested and there are a variety of artificial intelligence solutions under development (11-13). Further work needs to be done to establish if the accurate classification of PFNs can truly exclude malignancy. This may involve training of readers to identify key features, the testing of AI solutions and development of specific solutions to identify benign PFNs. However, the nodule prevalence and distribution insights contained in this new NELSON data sounds a note of caution that we would do well to heed for both training and predictive machine model development and validation. The 
overall prevalence of new fissure-attached nodules was four times less that of baseline, but the non-PFN proportion is double, and the proportion of non-PFN nodules that are malignant is 14 times, that of baseline. Given how the performance of malignancy prediction (whether human or machine) vary with prevalence, any predictive model must perform robustly well on both baseline and incidental screening data before it can be considered trustworthy (14).

Thirdly, although Han et al. have added to the literature supporting the benign nature of PFNs and this can probably be extrapolated to PFNs detected outside screening programmes, participants with a past history of cancer were excluded, so cannot safely exclude PFNs detected in this setting from follow-up. There is only anecdotal evidence of a higher rate of malignancy so further case series are needed.

Fourthly, current guidance recommends caution in larger PFNs $>10 \mathrm{~mm}$ in diameter. This should remain the case since most of the PFNs in the NELSON data were smaller than this. Although size remained the only metric that usefully distinguished malignant from benign non-PFNs, in practice it would seem (given the median mean diameter of $6 \mathrm{~mm}$ ) that the majority of malignant non-PFNs would have required CT surveillance only, rather than a more aggressive investigative strategy (there are no data provided about their growth rate).

The small sample size in this study notwithstanding, there are a few simple rules of thumb for any radiologist evaluating new fissure-attached nodules in incident screening rounds: (I) if it can be classified as a typical or atypical PFN, it probably is benign; (II) if it cannot be classified as typical or atypical, it has a 1 in 4 chance of malignancy; (III) treat a non-PFN as any other indeterminate nodule and use volumetry to assess its size; and (IV) be vigilant of larger fissure-attached nodules.

This evidence from the NELSON trial has again provided useful reassuring information that newly detected PFNs, like those detected at baseline, are benign. They are also an infrequent finding, representing only $4 \%$ of new nodules and $0.6 \%$ of all nodules detected over 5.5 years of screening. The importance of accurate reading of scans, using experts reaching a consensus and using the latest techniques to assist interpretation is emphasised by this study. Training of readers could substantially improve management of participants in screening and patients. Further work is needed in risk prediction for PFNs with atypical features, including larger size, and when they are detected in people with a previous history of malignancy.

\section{Acknowledgments}

Funding: None.

\section{Footnote}

Provenance and Peer Review: This article was commissioned by the editorial office, Translational Lung Cancer Research. The article did not undergo external peer review.

Conflicts of Interest: All authors have completed the ICMJE uniform disclosure form (available at: http://dx.doi. org/10.21037/tlcr-20-586). AN reports non-financial support from AIDENCE BV, grants from NIHR UCL Biomedical Research Centre, outside the submitted work. The other authors have no conflicts of interest to declare.

Ethical Statement: The authors are accountable for all aspects of the work in ensuring that questions related to the accuracy or integrity of any part of the work are appropriately investigated and resolved.

Open Access Statement: This is an Open Access article distributed in accordance with the Creative Commons Attribution-NonCommercial-NoDerivs 4.0 International License (CC BY-NC-ND 4.0), which permits the noncommercial replication and distribution of the article with the strict proviso that no changes or edits are made and the original work is properly cited (including links to both the formal publication through the relevant DOI and the license). See: https://creativecommons.org/licenses/by-nc-nd/4.0/.

\section{References}

1. de Koning HJ, van der Aalst CM, de Jong PA, et al. Reduced Lung-Cancer Mortality with Volume CT Screening in a Randomized Trial. N Engl J Med 2020;382:503-13.

2. Horeweg N, van Rosmalen J, Heuvelmans MA, et al. Lung cancer probability in patients with CT-detected pulmonary nodules: a prespecified analysis of data from the NELSON trial of low-dose CT screening. Lancet Oncol 2014;15:1332-41.

3. Callister ME, Baldwin DR, Akram AR, et al. British Thoracic Society guidelines for the investigation and management of pulmonary nodules. Thorax 2015;70 Suppl 2:ii1-ii54.

4. MacMahon H, Naidich DP, Goo JM, et al. Guidelines for 
Management of Incidental Pulmonary Nodules Detected on CT Images: From the Fleischner Society 2017.

Radiology 2017;284:228-43.

5. de Hoop B, van Ginneken B, Gietema H, et al. Pulmonary perifissural nodules on CT scans: rapid growth is not a predictor of malignancy. Radiology 2012;265:611-6.

6. Han D, Heuvelmans MA, van der Aalst CM, et al. New Fissure-Attached Nodules in Lung Cancer Screening: A Brief Report From The NELSON Study. J Thorac Oncol 2020;15:125-9.

7. van Klaveren RJ, Oudkerk M, Prokop M, et al. Management of lung nodules detected by volume CT scanning. N Engl J Med 2009;361:2221-9.

8. Schreuder A, van Ginneken B, Scholten ET, et al. Classification of CT Pulmonary Opacities as Perifissural Nodules: Reader Variability. Radiology 2018;288:867-75.

9. Radiology ACo. Lung-RADS® Version 1.1. 2019. Available online: https://www.acr.org/-/media/ACR/Files/ RADS/Lung-RADS/LungRADSAssessmentCategorie sv1-1.pdf?la=en

Cite this article as: Morgan H, O'Dowd EL, Nair A, Baldwin DR. New fissure-attached nodules in lung cancer screening: more practical implications from the NELSON study? Transl Lung Cancer Res 2020;9(5):2161-2164. doi: 10.21037/tlcr-20-586
10. Oudkerk M, Devaraj A, Vliegenthart R, et al. European position statement on lung cancer screening. Lancet Oncol 2017;18:e754-66.

11. Nair A, Screaton NJ, Holemans JA, et al. The impact of trained radiographers as concurrent readers on performance and reading time of experienced radiologists in the UK Lung Cancer Screening (UKLS) trial. Eur Radiol 2018;28:226-34.

12. Baldwin DR, Gustafson J, Pickup L, et al. External validation of a convolutional neural network artificial intelligence tool to predict malignancy in pulmonary nodules. Thorax 2020;75:306-12.

13. Ather S, Kadir T, Gleeson F. Artificial intelligence and radiomics in pulmonary nodule management: current status and future applications. Clin Radiol 2020;75:13-9.

14. Park SH, Han K. Methodologic Guide for Evaluating Clinical Performance and Effect of Artificial Intelligence Technology for Medical Diagnosis and Prediction. Radiology 2018;286:800-9. 